\title{
EXPERIMENTAL STUDIES ON TENSILE PROPERTIES OF JUTE FIBRE REINFORCED POLYMER COMPOSITES
}

\section{G. MUSALAIAH ${ }^{1}{ }^{1}$ BADE VENKATA SURESH $^{2}$, B. PRASHANTH $^{\mathbf{3}} \&$ B. DHANRAJ ${ }^{\mathbf{4}}$}

${ }^{I}$ Department of Mechanical engineering, Institute of Aeronautical Engineering, Dundigal Hyderabad, India

${ }^{2}$ Department of Mechanical Engineering, GMR Institute of Technology, Rajam, Andhra Pradesh, India

${ }^{3}$ Department of Mechanical Engineering, MLR Institute of Technology, Dundigal, Hyderabad, India

${ }^{4}$ Department of Mechanical Engineering, Vardhaman College of Engineering, Shamshabad, Hyderabad, India

\section{ABSTRACT}

As reinforcement material, jute fibre is used to develop reinforced plastics for the purpose of various engineering applications. Just because of its acceptable mechanical properties, low cost and biodegradability, it is chosen as reinforcement material. The mechanical properties of polymeric matrix composites based on jute fibrereinforced polymer composites have played a dominant role for a long time, in a variety of applications for their high specific strength and modulus. In the present work, mechanical properties of the composites, such as Tensile strength and tensile modulus were measured in dependence of fibre content.

Received: Jul 01, 2017; Accepted: Jul 20, 2017; Published: Aug 01, 2017; Paper Id.: IJMPERDAUG201732

\section{INTRODUCTION}

Jute is one of the best natural fibre in various engineering applications and it is second largest producer in the country after cotton it comes under the best fibre category. Raw jute is the industrial name of jute. The fibres of jute are usually3 feet to 13 feet long, Gassan, J et.al.,[1] identified the mechanical properties of natural-fibrereinforced thermo sets, as a result of optimization of the properties of tossa jute fibres by the use of a $\mathrm{NaOH}$ treatment process. Gassan, J et.al.,[2] studied the effectiveness of MAH-PP copolymers (graft copolymer of PP and maleic anhydride) as coupling agents in jute-polypropylene composites. Karmaker, A. C.,et.al.,[3] SYNOPSIS Composites with polypropylene (PP) and jute fiber were prepared by injection molding technique. Maleic anhydride-grafted polypropylene was added as coupling agent to improve the adhesion between jute fiber and PP. Senthilkumaar, S., et.a;.,[4] investigated the Feasibility of employing this jute fiber activated carbon (JFC) for the removal of Methyleneblue (MB) from aqueous solution. Plackett, D., et.al.,[5] Examined of composite fracture surfaces using electron microscopy showed voids occurring between the jute fibre bundles and the polylactide matrix in some cases. Size exclusion chromatography revealed that only minor changes in the molecular weight distribution of the polylactide occurred during the process. Rana, A. K.,[6] studied that with the use of compatilizerflexural strength and tensile as high as $100 \%$ and $120 \%$, respectively and impact strength with unnotched by $175 \%$. Gowda, T. M. et.al.,[7] evaluated the mechanical properties of woven jute fabric reinforced composites Jawaid, M., et.al.,[8] produced hybric composites by a technique called, hand lay-up by reinforcing oil palm and jute fibres along with epoxy and identified that the tensile properties are improved, Acha, B. A et.al. [9] studied the dynamic mechanical response and the short term creep-recovery behavior of composites made from bidirectional jute fabrics and polypropylene. Rahman, M. R et.al.,[10] manufactured composites by injection 
molding. The raw fibre was manufactured composites and oxidized is post treated with urotropine.

\section{PROPOSED METHOD OF STUDY}

\section{Composite Preparation}

For composite Processing, Hand lay-up technique is the best method. The processing of this technique is very simple and processing requirements are also very less. Initially, the mold surface is prepared with wood and release gel is sprayed on it to avoid polymer to stick on its surface. In order to get good surface finish of the product, thin plastic sheets are placed at the bottom and top of the mold. Now, the reinforcement is cut into pieces as per the size of the mold. Then, liquid form of thermosetting polymer is mixed with suitable hardener thoroughly, and slowly poured on the mat surface. With help of brush, uniformly spreading of polymer has to be done. After that, second layer of mat is taken and a roller is passed over it with some pressure to avoid air gaps. The entire process is repeated, until the required layers are obtained. After that, top mold plate is covered with plastic sheet by spraying release gel. By leaving the entire set up in room temperature or at specific temperature, the produced composite are collected and transferred for further process. The schematic representation of hand lay-up is shown in figure 1. The time of curing depends on type of polymer used for composite processing. For example, for epoxy based system, normal curing time at room temperature is $24-48$ hours.

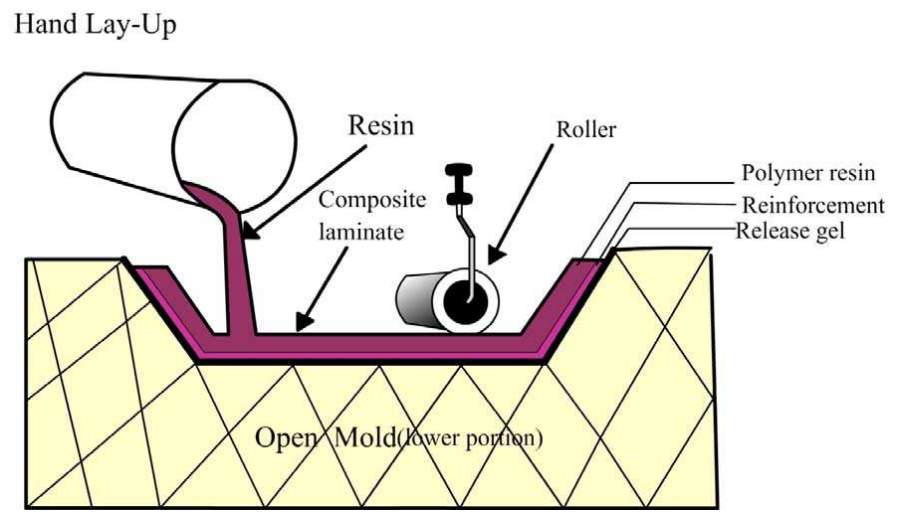

Figure 1: Hand Lay-Up Technique

\section{Jute Fibre Chemical Treatment}

Initially, the jute was cut into uniform standards of $200 \mathrm{~mm}$, and stored in a dry place. Then, taken to the laboratory and the jute was immersed in the distilled water and the $\mathrm{pH}$ value of the setup was checked, and it was observed around 6.20 and now, treated with alkaline solution to increase PH up to 7.00. The selected alkaline solution was NaoH. Taking $2 \%$ of $\mathrm{NaoH}$ in a beaker of pure distilled water, jute standards were immersed to $30 \mathrm{~min}$. And then, the $\mathrm{pH}$ value of it was checked, the PH gave 7.00 on PH meter. Then Stirring was stopped and taken out the jute, and air dried for 2 hours. Blower was used to blow the air for removing moisture and they were stored in a dry place.

\section{RESULTS AND DISCUSSIONS}

\section{Tension Test}

Tensile test was conducted at GITAM University and the results are tabulated in table 2 . The Tensile test on the specimen of the dimensions $200 \mathrm{~mm} \times 12 \mathrm{~mm} \times 12 \mathrm{~mm}$ was done by using Hydraulic Operated Computerized Universal Testing Machine (UTM) of measuring capacity of $( \pm 100 \mathrm{kN})$, with $150 \mathrm{~mm}$ of usable stroke. It was designed for both static and dynamic testing on a variety of a materials and components. 
Tensile test specimen specification:

$\begin{array}{ll}\text { Length : } & 200 \mathrm{~mm} \\ \text { Breath : } & 12 \mathrm{~mm} \\ \text { Height : } & 12 \mathrm{~mm}\end{array}$

Table 1: Tensile Test on Jute Composite

\begin{tabular}{|l|l|}
\hline Company & Gitam University \\
\hline Laboratory Name & Mechanical Testing Lab \\
\hline Rate 1 & $5.00000 \mathrm{~mm} / \mathrm{min}$ \\
\hline
\end{tabular}

Table 2: Raw Specimen Tensile Test on Glass Composite

\begin{tabular}{|c|c|c|c|c|c|c|}
\hline S. No & $\begin{array}{l}\text { Time } \\
\text { (sec) }\end{array}$ & $\begin{array}{l}\text { Load } \\
(\mathbf{N})\end{array}$ & $\begin{array}{l}\text { Extension } \\
\quad(\mathbf{m m})\end{array}$ & $\begin{array}{c}\text { Tensile } \\
\text { strain } \\
(\mathrm{mm} / \mathbf{m m})\end{array}$ & $\begin{array}{l}\text { Tensile stress } \\
\text { (MPa) }\end{array}$ & $\begin{array}{c}\text { Tensile } \\
\text { Extension } \\
(\mathbf{m m})\end{array}$ \\
\hline 1. & 1 & 0.08 & 0.02 & 0.00021 & 0.54529 & 0.01985 \\
\hline 2. & 2 & 0.15 & 0.04 & 0.00038 & 1.04734 & 0.03571 \\
\hline 3. & 3 & 0.22 & 0.05 & 0.00056 & 1.50581 & 0.0533 \\
\hline 4. & 4 & 0.28 & 0.07 & 0.00073 & 1.96027 & 0.06892 \\
\hline 5. & 5 & 0.34 & 0.08 & 0.00088 & 2.34812 & 0.08318 \\
\hline 6. & 6 & 0.4 & 0.1 & 0.00109 & 2.79997 & 0.10328 \\
\hline 7. & 7 & 0.46 & 0.12 & 0.00124 & 3.22254 & 0.11767 \\
\hline 8. & 8 & 0.53 & 0.13 & 0.00141 & 3.65017 & 0.13434 \\
\hline 9. & 9 & 0.58 & 0.15 & 0.00159 & 4.0572 & 0.1507 \\
\hline 10. & 10 & 0.64 & 0.17 & 0.00178 & 4.43548 & 0.16927 \\
\hline 11. & 11 & 0.7 & 0.19 & 0.00197 & 4.83092 & 0.18685 \\
\hline 12. & 12 & 0.75 & 0.2 & 0.00212 & 5.21742 & 0.20171 \\
\hline 13. & 13 & 0.81 & 0.22 & 0.00232 & 5.60289 & 0.22 \\
\hline 14. & 14 & 0.86 & 0.23 & 0.00247 & 5.97322 & 0.23498 \\
\hline 15. & 15 & 0.91 & 0.25 & 0.00266 & 6.33939 & 0.25289 \\
\hline 16. & 16 & 0.96 & 0.27 & 0.0028 & 6.69111 & 0.26642 \\
\hline 17. & 17 & 1.02 & 0.29 & 0.00302 & 7.07665 & 0.28697 \\
\hline 18. & 18 & 1.07 & 0.3 & 0.0032 & 7.45515 & 0.30415 \\
\hline 19. & 19 & 1.12 & 0.32 & 0.00336 & 7.79858 & 0.31943 \\
\hline 20. & 20 & 1.17 & 0.33 & 0.00351 & 8.11085 & 0.3339 \\
\hline 21. & 21 & 1.22 & 0.35 & 0.00372 & 8.49762 & 0.35311 \\
\hline 22. & 22 & 1.28 & 0.37 & 0.00391 & 8.86742 & 0.37128 \\
\hline 23. & 23 & 1.32 & 0.38 & 0.00406 & 9.16173 & 0.38562 \\
\hline 24. & 24 & 1.37 & 0.4 & 0.00423 & 9.5132 & 0.40163 \\
\hline 25. & 25 & 1.42 & 0.42 & 0.00439 & 9.83576 & 0.4174 \\
\hline 26. & 26 & 1.47 & 0.43 & 0.00456 & 10.19956 & 0.43361 \\
\hline 27. & 27 & 1.51 & 0.45 & 0.00477 & 10.51087 & 0.45355 \\
\hline 28. & 28 & 1.56 & 0.47 & 0.00495 & 10.82293 & 0.47062 \\
\hline 29. & 29 & 1.6 & 0.49 & 0.00513 & 11.14539 & 0.48781 \\
\hline 30. & 30 & 1.65 & 0.5 & 0.00528 & 11.4823 & 0.50176 \\
\hline 31. & 31 & 1.7 & 0.52 & 0.00546 & 11.8087 & 0.51887 \\
\hline 32. & 32 & 1.74 & 0.53 & 0.00563 & 12.10517 & 0.5352 \\
\hline 33. & 33 & 1.79 & 0.55 & 0.00582 & 12.42126 & 0.55251 \\
\hline 34. & 34 & 1.83 & 0.57 & 0.00599 & 12.74099 & 0.56938 \\
\hline 35. & 35 & 1.89 & 0.59 & 0.00618 & 13.09138 & 0.58685 \\
\hline 36. & 36 & 1.92 & 0.6 & 0.00634 & 13.36432 & 0.60217 \\
\hline 37. & 37 & 1.97 & 0.62 & 0.00649 & 13.66789 & 0.61689 \\
\hline 38. & 38 & 2.01 & 0.64 & 0.00672 & 13.98091 & 0.63811 \\
\hline 39. & 39 & 2.06 & 0.65 & 0.00686 & 14.29758 & 0.65218 \\
\hline
\end{tabular}




\begin{tabular}{|l|c|c|c|c|c|c|}
\hline \multicolumn{7}{|c|}{ Table 2: Contd., } \\
\hline 40. & 40 & 2.09 & 0.67 & 0.00704 & 14.52788 & 0.66881 \\
\hline 41. & 41 & 2.14 & 0.68 & 0.0072 & 14.84737 & 0.68413 \\
\hline 42. & 42 & 2.18 & 0.7 & 0.0074 & 15.16572 & 0.70346 \\
\hline 43. & 43 & 2.23 & 0.72 & 0.00757 & 15.45727 & 0.71888 \\
\hline 44. & 44 & 2.26 & 0.74 & 0.00775 & 15.6798 & 0.73597 \\
\hline 45. & 45 & 2.3 & 0.75 & 0.00792 & 15.99189 & 0.75193 \\
\hline 46. & 46 & 2.35 & 0.77 & 0.0081 & 16.30155 & 0.76922 \\
\hline 47. & 47 & 2.39 & 0.78 & 0.00827 & 16.58927 & 0.78561 \\
\hline
\end{tabular}

\section{Graph}

Tabulated Tensile values were plotted according to above table 2. The graphs are plotted to understand pictorially, whether there is increment or decrement in the tensile values on the specimen. Figure 2 shows the Graphs are plotted between Tensile stress $\left(\mathrm{N} / \mathrm{mm}^{2}\right)$ (Y-axis) and Tensile strain (X-axis) as follows.

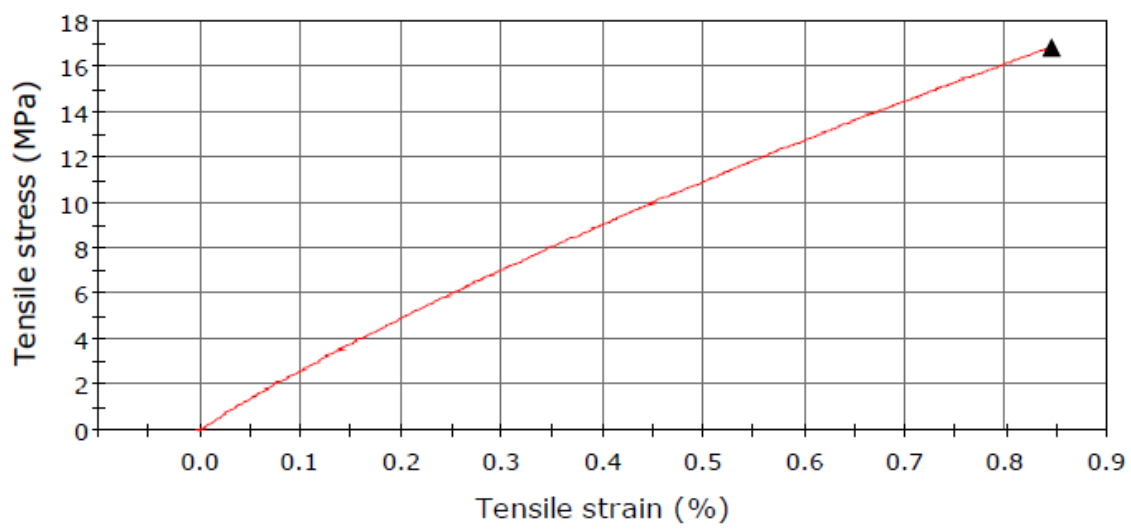

Figure 2: Stress vs. Strain Graph of Tension Test

Table 3: Tensile Test on the Specimen

\begin{tabular}{|c|l|c|c|c|c|c|}
\hline S. No & $\begin{array}{c}\text { Specimen } \\
\text { Label }\end{array}$ & $\begin{array}{c}\text { Maximum } \\
\text { Load (KN) }\end{array}$ & $\begin{array}{c}\text { Load at } \\
\text { Break(KN) }\end{array}$ & $\begin{array}{c}\text { UTS } \\
\text { (MPa) }\end{array}$ & $\begin{array}{c}\text { Load at 2\% } \\
\text { Strain (KN) }\end{array}$ & $\begin{array}{c}\text { Modulus } \\
\text { (E -Modulus) MPa }\end{array}$ \\
\hline 1 & Jute & 2.42052 & 2.42 & 16.81 & 5.69 & 19.776 \\
\hline
\end{tabular}

The initial load of $0.02 \mathrm{~N}$ to the maximum load of $2.42 \mathrm{~N}$ is given for the experiment. At the maximum load of $2.42052 \mathrm{~N}$, the breaking point occurs. The tensile extensions for initial and final values are $0.00204 \mathrm{~mm}$ and $0.8016 \mathrm{~mm}$, respectively. The tensile stress and strain values for initial conditions are $0.0058 \mathrm{MPa}$ and 0.00002 , respectively and for final conditions are $16.8092 \mathrm{MPa}$ and 0.00844 , respectively. The initial values are taken at the time $0.0008 \mathrm{sec}$ and the final values are taken at $47.9 \mathrm{sec}$.

The values of stress, strain and young's modulus for Tensile are as follows.

Tensile Test:

$\begin{array}{llc}\text { Yield Stress } & : & 5.3 \mathrm{MPa} \\ \text { Tensile Stress } & : & 16.81 \mathrm{MPa} \\ \text { Strain } & : & 5.69 \\ \text { Young's Modulus } & : & 19.776 \mathrm{MPa}\end{array}$




\section{CONCLUSIONS}

The values of stress, strain and young's modulus of tensile test were obtained by mixing the jute with epoxy resin and epoxy hardener. The ratio of epoxy resin to epoxy hardener used in this composite was 10:1. Due to this ratio, young's modulus of the composite increased. And, efficient methodology was established. With the above results, it is cleared that the tensile properties of the jute fibre reinforced composites are increasing, and it is biodegradable and there will be no effect on the environment.

\section{REFERENCES}

1. Gassan, J., \& Bledzki, A. K. (1999). Possibilities for improving the mechanical properties of jutelepoxy composites by alkali treatment of fibres. Composites Science and Technology, 59(9), 1303-1309.

2. Gassan, J., \&Bledzki, A. K. (1997). The influence of fiber-surface treatment on the mechanical properties of jutepolypropylene composites. Composites Part A: Applied Science and Manufacturing, 28(12), 1001-1005.

3. Karmaker, A. C., \&Youngquist, J. A. (1996). Injection molding of polypropylene reinforced with short jute fibers. Journal of Applied Polymer Science, 62(8), 1147-1151.

4. Senthilkumaar, S., Varadarajan, P. R., Porkodi, K., \&Subbhuraam, C. V. (2005). Adsorption of methylene blue onto jute fiber carbon: kinetics and equilibrium studies. Journal of colloid and interface science, 284(1), 78-82.

5. Plackett, D., Andersen, T. L., Pedersen, W. B., \& Nielsen, L. (2003). Biodegradable composites based on L-polylactide and jute fibres. Composites science and technology, 63(9), 1287-1296.

6. Rana, A. K., Mandal, A., Mitra, B. C., Jacobson, R., Rowell, R., \& Banerjee, A. N. (1998). Short jute fiber-reinforced polypropylene composites: effect of compatibilizer. Journal of Applied Polymer Science, 69(2), 329-338.

7. Gowda, T. M., Naidu, A. C. B., \& Chhaya, R. (1999). Some mechanical properties of untreated jute fabric-reinforced polyester composites. Composites Part A: applied science and manufacturing, 30(3), 277-284.Polyester Composites. Composites: Part A, 30, 277-284.

8. Jawaid, M., Khalil, H. A., Hassan, A., Dungani, R., \&Hadiyane, A. (2013). Effect of jute fibre loading on tensile and dynamic mechanical properties of oil palm epoxy composites. Composites Part B: Engineering, 45(1), 619-624.

9. Acha, B. A., Reboredo, M. M., \& Marcovich, N. E. (2007). Creep and dynamic mechanical behavior of PP-jute composites: Effect of the interfacial adhesion. Composites Part A: Applied Science and Manufacturing, 38(6), 1507-1516.

10. Rahman, M. R., Huque, M. M., Islam, M. N., \& Hasan, M. (2008). Improvement of physico-mechanical properties of jute fiber reinforced polypropylene composites by post-treatment. Composites Part A: Applied Science and Manufacturing, 39(11), 1739-1747. 
